\title{
O TRATAMENTO DA PRONÚNCIA NOS MATERIAIS DIDÁTICOS DE PORTUGUÊS COMO LÍNGUA ADICIONAL
}

\author{
THE TREATMENT OF PRONUNCIATION IN PORTUGUESE TEXBOOK \\ AS ADDITIONAL LANGUAGE
}

José Henrique Santos Tavares ${ }^{1}$

Natália Cristine Prado ${ }^{2}$

\section{Resumo}

O objetivo desta pesquisa é analisar como os livros didáticos de português, como Língua Adicional (PLA), direcionam o ensino da pronúncia desse idioma para hispanofalantes. O material analisado é o primeiro módulo de PLA do e-Tec Idiomas Sem Fronteiras. Pretende-se analisar os conteúdos que abordem, de forma direta ou indireta, a fonética, a fonologia do português (PB). A investigação é exploratória e fará uso de procedimentos diretos. Para o alcance dos objetivos propostos, realizamos a revisão da literatura sobre o ensino-aprendizagem de PLA, de fonética e fonologia e de pronúncia, que deram o embasamento teórico para o desenvolvimento da investigação. Com este estudo, observou-se que os áudios da mídia integrada priorizam apenas as variedades do português do sul do Brasil, o que pode estimular nos alunos uma falsa sensação de homogeneidade linguística, além de dificultar o ensino de pronúncia para os hispanofalantes residentes em regiões da fronteira amazônica.

\section{Palavras-Chave}

Hispanofalantes. Livro didático. PLA. Ensino de Pronúncia.

\begin{abstract}
The objetive of this research is to analyze how the textbooks of portuguese, as additional language (PAL), direct the teaching of the pronunciation of this language to speakers of the spanish The material analyzed is the first PAL module of the E-Tec languages Sem Fronteiras. Intend analyze the contents that treat, directly or indirectly, the phonetics, the phonology of portuguese (brasilian portuguese). The investigation is exploratory and will use direct procedures. To achieve the proposed objectives, we conducted a review of the literature on the teaching-learning of $P A L$, phonetics and phonology and pronunciation, which gave the theoretical basis for the development of the investigation. With this study, it was observed that the audios of the integrated media prioritize only the portuguese varieties of south of the Brazil, which can stimulate in the students a false sense of linguistic homogeneity, besides hindering the teaching of pronunciation to the the speakers of the spanish residents in regions of the amazon border.
\end{abstract}

\section{KeYWORDS}

Speakers of the spanish. Textbook. PAL. Teaching pronunciation.

1 Mestrando em Letras pela Universidade Federal de Rondônia, professor do Instituto Federal de Rondônia/Campus GuajaráMirim.

2 Doutora em Linguística e Língua Portuguesa pela Faculdade de Ciências e Letras - UNESP - Araraquara, professora da Universidade Federal de Rondônia. 


\section{INTRODUÇÃo}

O objetivo principal deste artigo é analisar como os materiais didáticos desenvolvem o ensino da pronúncia do português brasileiro para aprendentes hispanofalantes, bem como investigar conteúdos que abordem aspectos da fonética e da fonologia no ensino de línguas estrangeiras. Este trabalho surge da necessidade de pesquisar essa temática não tão estudada no ensino-aprendizagem do português por falantes de outras línguas. Assim, estudando essa temática pode-se contribuir para a reflexão sobre o papel dos materiais didáticos no ensino da pronúncia de PLA, pois oportuniza a discussão sobre a adequação desses livros frente às necessidades de alunos e professores que participam do processo de ensino-aprendizagem de PLA.

Pretende-se realizar uma revisão sobre a literatura que aborda de forma histórica o surgimento português como língua adicional (PLA) no Brasil até os dias atuais, com o objetivo de situar os períodos temporais que permeiam a temática do ensino-aprendizagem de português para falantes de outras línguas. Em seguida, apresenta-se a caracterização do material didático e a estruturação do módulo analisado, os aspectos inerentes a pronúncia nos materiais didáticos e por último será realizada a análise dos cadernos que integram o módulo que viabilizará a análise.

\section{Breve histórico do Português como língua adicional no Brasil}

Melo et al. (2013) afirmam que houve quatro momentos relevantes do ensino e da pesquisa do PLA: o primeiro está relacionando ao ensino do português europeu pelos padres jesuítas aos indígenas; o segundo refere-se ao período da segunda metade do século XIX até o início do século XX e diz respeito à imigração europeia no Brasil; o terceiro abrange o ensino-aprendizagem de português como língua estrangeira em nível internacional; o quarto e último relaciona-se ao ensino de PLA no Brasil na atualidade.

Segundo Almeida Filho,

o ensino de português para falantes de outras línguas e participantes de outras culturas existe como prática no Brasil desde o seu início colonial. A consciência generalizada de que essa é uma área de atuação profissional acadêmico-científica pode ser datada em pouco mais de 20 anos (ALMEIDA FILHO, 2012, p. 723).

Ainda segundo o autor, há indícios significativos acerca do surgimento da nova especialidade no ensino de línguas no Brasil.

O primeiro indicio foi a abertura de cursos para alunos estrangeiros no Sul do Brasil. A Pontifícia Universidade Católica do Rio Grande do Sul (PUC-RS) foi uma das pioneiras na oferta de cursos de português como língua estrangeira. A professora Mercedes Marchand elaborou, em 1957, o manual didático O ensino de português para estrangeiros pela Editora Meridional Sulina do Rio Grande do Sul.

Nos anos 1960, houve uma crescente demanda de criação de cursos superiores de português em universidades dos Estados Unidos, além da produção do livro Modern Portuguese, em 1966, por um seleto grupo de especialistas no ensino de línguas - como o linguista aplicado pernambucano Francisco Gomes de Matos e a escritora cearense Dinah Silveira de Queiroz, que era a responsável pela elaboração de diálogos do material didático. 
A década seguinte assiste à criação de cursos de PLE para estrangeiros na USP e na UNICAMP, no ano de 1976. Soluções administrativas muito distintas para a implantação mostram o acerto da UNICAMP em instituir o PLE como disciplina de catálogo e permitir a contratação de docentes pesquisadores de carreira para seu quadro. Com o passar dos anos, esse acerto frutificaria com várias iniciativas de consolidação da área a partir do Departamento de Linguística Aplicada, que abrigou a emergente área com grande visão de futuro. A USP, ao contrário, implantou o PLE como extensão desvinculada da graduação e da pós-graduação. Essa providência não prejudicou a oferta de cursos ao grande contingente de alunos estrangeiros na Instituição, mas também não alçou o trabalho de ensino do Português para Estrangeiros a níveis mais impactantes de estabelecimento da nova especialidade (ALMEIDA FILHO, 2012, p. 726).

Almeida Filho considera que a instalação do PLE nessas duas grandes universidades paulistas, em 1976, fosse consolidar a área com autenticidade; no entanto, somente na segunda metade da década de 1980 surgiram as primeiras das diversas coletâneas de artigos sobre o ensino de PLE, sob coordenação acadêmica dele próprio (ALMEIDA FILHO, 1989).

Ainda por ser muito recente, não se dispunha de literatura específica, no Brasil e em Portugal, acerca dos aspectos do ensino de português para falantes de outras línguas. Várias iniciativas impulsionaram e consolidaram a área do PLE: a criação da Sociedade Internacional para o Português Língua Estrangeira (SIPLE), nos anos 1990; o Exame Nacional de Proficiência em PLE (ENPE); o Exame para obter o Certificado de Proficiência em Língua Portuguesa para Estrangeiro (Celpe-Bras), instituído a partir do recém criado ENPE, coordenado e pilotado por Almeida Filho nos países do Tratado de Assunção em anos anteriores; a realização de congressos nacionais e internacionais; publicações de livros e edições especiais de revistas universitárias sobre o tema do ensino de PLE e a apresentação de resultados de projetos de pesquisa de Mestrado e Doutorado acerca de temas relativos à agenda brasileira para o PLE.

Segundo Zoppi-Fontana e Diniz (2008), com a visibilidade mais acentuada e a participação do Brasil no cenário político-econômico por meio do Mercado Comum do Sul (Mercosul) a partir de 1991, com a assinatura do Tratado de Assunção, houve a criação de novos espaços para a veiculação da língua nacional. Esses novos acontecimentos evidenciaram a necessidade de desenvolver saberes metalinguísticos e instrumentos linguísticos do português brasileiro (PB) que fossem adequadamente legitimados.

Para Escarpinete (2012), a criação do Celpe-Bras, em 1993, foi uma das importantes ações que destacou e difundiu o ensino de PLE em nosso país. Além do Brasil, que recebe muitos estrangeiros em busca de formação superior, o exame é aplicado em vários países. Segundo Machado,

as últimas décadas do século XX foram movimentadas pelo desenvolvimento de intercâmbios econômicos, científicos culturais entre o Brasil e os mais diferentes países, o que impôs ao Brasil a criação de meios legais para incentivar, estruturar e legitimar tais acordos. Isso, devido à língua portuguesa ocupar um lugar fundamental nas relações com falantes dos mais diversos países, mas, sobretudo, para responder à necessidade de validação de cursos e formações realizadas no Brasil. De modo que, como parâmetro para a comprovação do domínio do português do Brasil, o Estado brasileiro elabora o CELPE-Bras (MACHADO, 2011, p. 71-2). 
Almeida Filho defende que são necessários mais incentivos oriundos de políticas governamentais em favor da consolidação do ensino e da oferta de português língua estrangeira em nosso país. Esse autor reitera que:

dada a sua condição de país pós-colonial economicamente emergente, a responsabilidade brasileira pela língua e seu ensino numa circulação global tem demorado a se converter em políticas deliberadas e concertadas, entre elas a do ensino do Português como língua segunda e/ou estrangeira (ALMEIDA FILHO, 2008, p. 13).

Mário Vieira de Carvalho, em seu artigo "Língua Portuguesa e Ciência" (JORNAL PÚBLICO, 29 dez. 2013), argumenta que sejam publicados mais trabalhos em língua portuguesa. Defende que as línguas portuguesa e espanhola, assim como a alemã e a francesa, também podem ser línguas de referência nos trabalhos acadêmicos, devido às significantes produções acadêmicas. Portanto, “publicar em português ou em espanhol é publicar em línguas internacionais". Sem descredibilizar as publicações em língua inglesa, que é um referencial para internacionalização da pesquisa, o autor afirma que:

seria um erro reduzir a produção e a circulação de conhecimento científico a uma única língua veicular. Também o latim o foi durante séculos, acabando destronado pelo uso do vernáculo. Não há razão para crer que os processos históricos de hegemonia e contra-hegemonia de tal ou tal língua na comunicação científica estejam encerrados. Pelo contrário, é plausível que a atual "correlação de forças" se altere num futuro mais ou menos próximo (CARVALHO, 2013).

Segundo Allegro (2014), a necessidade de ensinar e aprender língua portuguesa está estabelecida; no entanto, algumas iniciativas são incertas, pois não se sabe se serão duradouras. Em 2013, foi criado o Portal do Professor de Português Língua Estrangeira (PPPLE) durante a II Conferência Internacional sobre o Futuro da Língua Portuguesa no Sistema Mundial (Lisboa, 2013), que propunha atividades para todas as variantes do português, como foi previsto no Plano de Ação de Brasília (PAB) em 2010.

Ainda nas palavras da autora, o ensino de português tem longa tradição e forte reconhecimento fora do Brasil; apoiados pelo governo brasileiro, os Centros de Estudos Brasileiros (CEBs) ${ }^{3}$ atuam junto às embaixadas no exterior.

O perfil dos alunos tem se modificado nos últimos anos nos institutos de idiomas no exterior. Se antes os alunos buscavam aulas de português visando o turismo ou a leitura dos romances, atualmente é comum encontrarmos executivos que começam a estudar por participarem de relações comerciais entre os países, estudantes com o projeto de estudar no Brasil e, logicamente, as pessoas que querem visitar o país pelos eventos esportivos. Passou a ser, também e pelo ensino nas escolas no exterior, escutar que crianças estão aprendendo o idioma (ALLEGRO, 2014, p. 24).

A expansão no ensino-aprendizagem de português como segunda língua (L2) nos últimos anos deu-se, essencialmente, devido a fatores profissionais, pessoais, turísticos e/ou comerciais. Esses fatores ratificam a necessidade de haver uma formação de excelência para os estrangeiros

3 O Centro de Estudos Brasileiros (CEB) foi fundado no dia 10 de setembro de 1974, em Assunção, capital paraguaia, em substituição ao Instituto Cultural Paraguai-Brasil. É composto por três setores: o da Língua Portuguesa, o de Artes Plásticas e a Escola de Arte. 
que não falam a língua por meio de uma abordagem didático-pedagógica qualitativa, a fim de que eles possam, nos variados contextos sociais de comunicação, acompanhar o progresso linguístico do português como língua adicional, nas relações com falantes portugueses e vice-versa. Segundo Allegro,

o interesse pelo ensino de Português Língua Estrangeira (PLE) tem aumentado no contexto internacional, em consonância com a importância que o Brasil adquiriu mais recentemente no cenário econômico desde que passou a configurar como uma das futuras potências mundiais, os BRICS (Brasil - Rússia - Índia - China-África do Sul) (ALLEGRO, 2014, p. 14).

Devido à posição geográfica do Brasil, diversos municípios fazem fronteira com países de língua espanhola. A procura por cursos de português como língua estrangeira é muito recorrente em território brasileiro, pois sua aprendizagem facilita a comunicação nas relações econômicas, sociais e profissionais. O português como língua adicional é relevante em razão de que seus contextos comunicativos têm se disseminado consideravelmente. Perna e Sun revelam que a língua portuguesa é a

\begin{abstract}
segunda língua românica, terceira língua europeia, quarta língua mais falada como língua adicional, quinta com maior número de países de língua oficial, espalhados pelos cinco continentes e sexta língua mundial. Além disso, até 2010, o português foi a $5^{a}$ língua mais falada na Internet com 82,5 milhões de usuários. Nas redes sociais, a língua portuguesa aparece como a $3^{\mathrm{a}}$ língua mais usada no Twitter e 9 $9^{\mathrm{a}}$, no Facebook (PERNA; SUN, 2011, p. 60).
\end{abstract}

Nesse sentido, percebe-se o crescimento da língua portuguesa no mundo, sobretudo nos espaços sociais em que as pessoas desenvolvem a comunicação; as tecnologias de comunicação e informação intensificam esse processo de expansão da língua.

É nesta perspectiva que se considera o português como língua adicional para hispanofalantes, uma vez que as palavras em língua portuguesa e em língua espanhola são consideravelmente similares - ainda que, a respeito das semelhanças, o falante de língua espanhola precise ter cuidado com a pronúncia e os sentidos da língua portuguesa.

A falta de experiência linguística e comunicativa é um dos fatores que dificultam o diálogo, sobretudo entre línguas bastante semelhantes. É imprescindível que o indivíduo em fase de aquisição do português como língua adicional participe de interações comunicativas em ambientes reais - tanto em redes sociais quanto em outros espaços frequentados pelos falantes.

Segundo Bakhtin (2003), a dificuldade na comunicação está associada à falta de experiência do usuário da língua com determinados gêneros do discurso em diferentes esferas de atividade humana.

Desse modo, os alunos hispanofalantes precisam ser aproximados de determinados gêneros do discurso e estratégias para desenvolver experiências comunicativas que estimulem a praticidade linguística entre ambas as línguas. Para isso, o professor precisa favorecer espaços de interações reais e oferecer materiais didáticos que auxiliem nesse processo de ensino-aprendizagem. 


\section{Caracterização do material didático}

O material didático analisado neste trabalho é o primeiro módulo do curso Português como Língua Adicional, que integra o programa e-Tec Idiomas sem Fronteiras, criado pelo governo federal brasileiro, é composto por 6 cadernos e midias integradas, foram produzidos pela Coordenadoria de Produção e Tecnologia Educacional do Instituto Federal de Educação, Ciência e Tecnologia Sul-rio-grandense(Pelotas/2015).

Segundo o Guia do Formador o Programa e-Tec Idiomas Sem Fronteiras surgiu de um estudo do Fórum de Relações Internacionais (FORINTER), vinculado à Câmara de Relações Internacionais do Conselho de Instituições de Educação Profissional Científica e Tecnológica (Conif) que detectaram a demanda por oferta de cursos de idiomas. A partir dessas pesquisas, observou-sea carência de oferta de línguas estrangeiras e conhecimento de idiomas estrangeiros na Rede de Educação Profissional, Científica e Tecnológica (EPCT), o espanhol e o inglês, idiomas essenciais para desenvolver os programas de mobilidade e capacitação dos estudantes para o mundo dotrabalho.

O programa busca complementar a formação de estudantes e servidores da Rede de Educação Profissional, Científica e Tecnológica (EPCT) e capacitá-los à comunicação eficaz em uma língua estrangeira e prepará-los para a realização de provas de proficiência e participação em programas de intercâmbio, além ampliar os conhecimentos acerca da cultura dos países visitados pelos intercambistas.

O Referencial pedagógico dos cursos do e-Tec Idiomas Sem Fronteiras foi pautado nos parâmetros do Quadro Europeu Comum de Referência para as Línguas (QECR) que categoriza os níveis de conhecimento e as etapas da lingua estrangeira como segunda língua.

\section{Niveis Do QECR}

- Iniciantes (A1 e A2), Independentes (B1 e B2) Proficientes (C1 e C2)

Os cursos do Programa e-Tec Idiomas Sem Fronteiras foram desenvolvidos em três módulos e cada um estabele relação com os níveis do QECR:

- Módulo 01 - nível A1; Módulo 02 - nível A2.

Deste modo, ao concluir os 3 módulos, espera-se que o estudante esteja apto a se comunicar em um nível de compreensão linguística para realizar as provas de proficiência referentes à cada idioma.

O material faz uso de temas transversais e preza pelo desenvolvimento comunicativo que vai além do âmbito da linguística, abordando temáticas como as socio-histórico-culturais e geográfico-ambiental.

De acordo com o guia do formador, o material faz uso da abordagem comunicativa no ensino de línguas, pois leva o aprendente a desenvolver as habilidades comunicativas de modo mais autêntico, onde a gramática é apresentada indutivamente.

O material didático faz uso de diversas estratégias, a narrativa de uma história para promover um vínculo e cativar o aprendente é uma delas, por meio de personagens animados relacionam os conteúdos trabalhados em cada aula a histórias do cotidiano, contribuindo para o aperfeiçoamento das habilidades comunicativas como a leitura e compreensão auditiva. As aulas ocorrem de modo 
gradual e no formato de uma série de televisão, cada episódio é abordado um conteúdo relacionado com a aula.

Os módulos são flexíveis, o professor responsável pela formação pode adequar as atividades fora dos cadernos, permitindo a inclusão de outros exercícios no ambiente virtual de aprendizagem Moodle de acordo com as especificidades de cada grupo de alunos.

\section{A estrutura do módulo 1 de Português como língua adicional}

Os cadernos do Módulo II, do curso de Português como língua adicional (PLA), foram planejados com o objetivo de desenvolver as habilidades comunicativas propostas no Quadro Europeu Comum de Referência para as Línguas (QECR), o nível desenvolvido neste material é o A1, direcionado aos hispanofalantes aprendentes do português básico.

Segundo o guia do formador, o material busca trabalhar as necessidades comunicacionais reais do cotidiano por meio de expressões familiares simples, para que o aprendente possa interagir, se localizar e encontrar lugares para se alimentar.

O curso completo tem duração de 200 horas de estudo, que devem concluídas em 20 semanas foram previstas em torno de $200 \mathrm{~h}$ de estudo, que devem ser efetuadas no período de 20 semanas. A primeira e a última aula são presenciais, respectivamente, uma para que os aprendentes conheçam e se ambientem ao AVA Moodle e a outra para avaliação final.

O módulo 1 é composto por três cadernos e cada caderno inclui 6 aulas, que prevê a duração de $10 \mathrm{~h}$ por aula, que deverão ser concluídas em uma semana.

Figura 1. Estrutura do módulo 1

\begin{tabular}{|l|l|l|}
\hline \multicolumn{3}{|c|}{ AÇÕES COMUNICATIVAS } \\
\hline \multicolumn{1}{|c|}{ AULA 1 } & \multicolumn{1}{|c|}{ AULA 2 } & \multicolumn{1}{c|}{ AULA 3 } \\
\hline $\begin{array}{l}\text { Reconhecer nome de } \\
\text { eventos acadêmicos e } \\
\text { apresentar-se em uma } \\
\text { entrevista de emprego ou } \\
\text { estágio. }\end{array}$ & $\begin{array}{l}\text { Planejar ações que serão } \\
\text { desenvolvidas no futuro. }\end{array}$ & $\begin{array}{l}\text { Contar uma viagem } \\
\text { realizada. }\end{array}$ \\
\hline \multicolumn{1}{|c|}{ AULA 4 } & AULA 5 & \multicolumn{1}{|c|}{ AULA 6 } \\
\hline $\begin{array}{l}\text { Comentar pequenas notí- } \\
\text { cias de jornais, narrar um } \\
\text { acontecimento importante } \\
\text { realizado no passado. }\end{array}$ & $\begin{array}{l}\text { Descrever e caracterizar } \\
\text { pessoas relacionando-as a } \\
\text { acontecimentos passados. }\end{array}$ & $\begin{array}{l}\text { Narrar ações realizadas ao } \\
\text { longo do dia. }\end{array}$ \\
\hline
\end{tabular}

Fonte: Guia do estudante (2015). 
Figura 2. Deição do caderno 1

\begin{tabular}{|l|l|l|}
\hline \multirow{2}{*}{01} & \multicolumn{1}{|c|}{ AULA } & \multicolumn{1}{c|}{ TÍTULO } \\
\hline \multirow{4}{*}{01} & 01 & Bem- vindo ao condomínio Brasil \\
\cline { 2 - 3 } & 02 & Fazendo amigos! \\
\cline { 2 - 3 } & 03 & Onde fica o mercado? \\
\cline { 2 - 3 } & 04 & Vamos de ônibus ou a pé? \\
\cline { 2 - 3 } & 05 & Alguém sabotou nossa feijoada! \\
\cline { 2 - 3 } & 06 & Compras no antiquário \\
\hline
\end{tabular}

Fonte: Guia do estudante (2015).

Figura 3. Descrição do caderno 1

\begin{tabular}{|l|l|l|}
\hline CADERNO & \multicolumn{1}{|c|}{ AULA } & \multicolumn{1}{c|}{ TíTULO } \\
\hline 02 & 07 & Uma família interessante \\
\cline { 2 - 3 } & 08 & Chegadas e partidas \\
\cline { 2 - 3 } & 09 & Atitudes saudáveis \\
\cline { 2 - 3 } & 10 & Uma noite de tempestace \\
\cline { 2 - 3 } & 11 & Vamos comer uma pizza? \\
\cline { 2 - 3 } & 12 & O que você sente? \\
\hline
\end{tabular}

Fonte: Guia do estudante (2015).

Figura - 4 Descrição do caderno 3

\begin{tabular}{|l|l|l|}
\hline CADERNO & \multicolumn{1}{|c|}{ AULA } & \multicolumn{1}{c|}{ TÍTULO } \\
\hline 03 & 13 & Escolhas profissionais e planos futuros \\
\cline { 2 - 3 } & 14 & Um desafio acadêmico \\
\cline { 2 - 3 } & 15 & E se eu pudesse viajar? \\
\cline { 2 - 3 } & 16 & Que tudo corra bem \\
\cline { 2 - 3 } & 17 & Organizando documentos para viagem \\
\cline { 2 - 3 } & 18 & Revisão \\
\hline
\end{tabular}

Fonte: Guia do estudante (2015).

As temáticas foram escolhidas com base no QECR e as ações comunicativas foram elaboradas de acordo com as necessidades do público-alvo. Já os conteúdos linguísticos são apresentados gradativamente, já que cada aprendente possui o seu tempo de aprendizagem e vai adquirindo cada habilidades comunicativas necessárias para obtenção do Nível A1 do curso de Português como Língua Adicional. 


\section{ENSINO dA PRONUNCIA do PORTUGUÊS COMO LÍNGUA ADICIONAL}

Farias (2015) define a pronúncia como o conjunto dos aspectos articulatórios e perceptivos de aspectos segmentais e suprassegmentais de uma língua, que equivalem respectivamente à pronúncia de vogais e consoantes e entonação, acento, ritmo, pausa, velocidade de elocução

Llisterri (2003) expõe as diferenças entre o ensino da pronúncia e da fonética. O ensino da fonética é compreendido pela promoção do conhecimento formal e minucioso das características articulatórias, acústicas e perceptivas dos segmentos e suprassegmentos de uma língua, já o ensino da pronúncia é compreendido pela integralização da prática da oralidade em sala de aula, aspecto que os aprendizes ao aprender um idioma deveriam dominar. Para Falcão,

\footnotetext{
a pronúncia pode ser entendida como o conjunto dos aspectos articulatórios e perceptivos de elementos segmentais (pronunciação de vogais e consoantes) e suprassegmentais (entoação, acento, ritmo, pausas, velocidade de elocução) de uma língua. Sua importância deriva de sua atuação fundamental no desenvolvimento das habilidades orais de produção e compreensão, pois é através do conhecimento sobre como os sons são articulados, suas características, a velocidade da fala e particularidades de entoação que os alunos serão capazes de produzir e distinguir sons e também estruturas prosódicas do idioma estudado, tornando-o inteligível (FALCÃO, 2012, p. 01).
}

Segundo (BAUER, ALVES, 2011, p. 287), “o ensino de pronúncia na sala de aula de Língua Estrangeira (LE) sempre constituiu uma questão controversa, sendo, muitas vezes, erradicado da prática dos professores de língua”. Os autores acrescentam os materiais didáticos atuais não evidenciam o ensino dos aspectos fonético-fonológicos, já que as obras disponíveis no mercado não integram o ensino da pronúncia às outras habilidades linguísticas.

Farias (2015), ao fazer uma abordagem histórica do ensino-aprendizagem de línguas estrangeiras menciona que o destaque dado ao ensino da pronúncia passou por mudanças significativas, perpassando pelo método tradicional (gramática e tradução), no qual se omitia o ensino da pronúncia, pelo audiolingual que tinha como objetivo principal o alcance da pronúncia muito semelhante ou idêntica à de falante um nativo e pela abordagem comunicativa que paulatinamente recupera a relevância do ensino da pronúncia no ensino de LE.

Blanco (2014), afirma em sua tese de doutorado que maioria dos livros didáticos voltados ao ensino básico de línguas estrangeiras destinam algumas páginas das primeiras seções de livros ao ensino da pronúncia e nos níveis posteriores não abordam esta temática. Constata que os manuais apresentam atividades que priorizam o ensino dos elementos segmentais e suprassegmentais que são menos recorrentes.

Segundo Allegro (2014, p. 77), "os exercícios com o propósito de ajudar o aluno a desenvolver as habilidades de pronúncia e de compreensão oral devem fazer parte da rotina de trabalho na sala de aula, assim como são trabalhadas a compreensão leitora e a produção escrita". Segundo a autora supracitada, algumas instituições de ensino não possuem recursos tecnológicos e ambientes adequados para oferecer o ensino da pronúncia em sala de aula. Ainda segundo Allegro:

o dado concreto é que no ensino atual, o tempo e a atenção dedicados ao ensino da pronúncia e da compreensão oral na LE não são nem proporcionais à sua relevância na aprendizagem do idioma, nem iguais aos que são dedicados à gramática ou outros aspectos linguísticos. A sensação que dá é que o simples fato de escutar o professor, uma 
música ou um programa de televisão faz os sons se internalizarem e o aluno ouvinte, como num passe de mágica, passa a pronunciar corretamente as diferenças fônicas e compreende o novo idioma em todas as situações (ALLEGRO, 2014, p. 78).

Monghaddam et al apud Allegro (2014) apud menciona que o ensino da pronúncia nunca esteve entre as prioridades didáticas dos docentes. Barbosa (2013) afirma que atualmente o ensino da pronúncia é um "ponto muito sensível” para muitos professores e GIL (2007, p. 31) reforça que a pronúncia é o aspecto mais desconsiderado no ensino de línguas estrangeiras.

A pronúncia de palavras e frases curtas encadeadas na precária comunicação que se permite nos níveis iniciais é, sem dúvida, uma preocupação dos aprendizes. Os alunos querem dominar os fonemas da nova língua e sua articulação e, por isso, repetem e repetem palavras dentro de suas mentes e até externamente para confirmar que estão avançando. Por isso valorizam tanto uma certa harmonia da variante dialetal nessa fase inicial. A ênfase inicial e premeditada e explicita nos fonemas esconde outro desafio: o modo como são encadeados, acentuados, ritmados e entonados os enunciados na língua que se quer adquirir (ALMEIDA FILHO, 2016, p. 148).

$\mathrm{O}$ autor reitera que os professores de línguas frequentemente não focam nos elementos suprassegmentais, mas há um crescimento conforme os fonemas são manipulados pelos novos aprendizes. Segundo Almeida Filho, os elementos suprassegmentais "são aspectos da pronúncia que se apresentam para além dos segmentais fonêmicos vocálicos ou consonantais". Ainda segundo o autor, os linguistas afirmam que os elementos suprassegmentais pertencem à prosódia, isto é, pertence ao campo dos fatos fônicos.

O dado concreto é que no ensino atual, o tempo e a atenção dedicados ao ensino da pronúncia e da compreensão oral na LE não são nem proporcionais à sua relevância na aprendizagem do idioma, nem iguais aos que são dedicados à gramática ou outros aspectos linguísticos. A sensação que dá é que o simples fato de escutar o professor, uma música ou um programa de televisão faz os sons se internalizarem e o aluno ouvinte, como num passe de mágica, passa a pronunciar corretamente as diferenças fônicas e compreende o novo idioma em todas as situações (ALLEGRO,2014, p. 78).

Segunda a autora, o ensino da pronúncia apesar de relevante na aprendizagem de uma língua adicional é deixado à margem, dando lugar aos estudos gramaticais, e quando há a intenção de se trabalhar este componente em sala de aula, os professores utilizam recursos didáticos que não surtem muito efeito na aprendizagem e na compreensão do sons da LE, já que os alunos estão sendo expostos à apenas a uma situação específica.

Para Fernández (2007, p.18), “a prática da pronúncia é considerada como atividade secundária, inclusive irrelevante, nos currículos orientados comunicativamente"

Fernández argumenta que

é imprescindível que o professor inclua a boa qualidade da pronúncia dos alunos entre os objetivos fundamentais a que se há de encaminhar seu trabalho docente. Se há de aspirar por princípio o mais alto grau de precisão e esmero, mas, claro está, a hora de fixar a ênfase que deverá conceder à pronúncia dentro de um programa, o professor necessariamente terá de ter em conta as variações individuais e psicológicas dos alunos, a língua materna de que parte, e os fatores sociais, culturais e educativos que rodeiam em cada caso ao processo de aprendizagem (FERNÁNDEZ, 2007, p. 100). 
Diante das problemáticas supracitadas, é possível organizar e planejar a abordagem dos sons a serem trabalhados de forma planejada. Llisterri (2003), explana que para esse planejamento é necessário realizar a definição dos objetivos com base no desenho curricular ou no planejamento do curso. Segundo Allegro,

o professor é quem decide a variedade a ser estudada, geralmente adotando a própria, já que é inviável mudar a própria pronúncia só para agradar a um grupo de alunos. No entanto, durante o curso, devem ser oferecidos exemplos de vários sotaques que o idioma tiver, estando preparado para responder as perguntas que possam surgir em classe. Outro aspecto a ser trabalhado são os diferentes graus de formalidade (ALLEGRO, 2014, p. 81).

Outras pesquisas como as de Iruela (2004) e Rigol (2005) confirmam as afirmações anteriores e acrescentam que a prática da pronúncia se desvincula das atividades orais e se desenvolve através da língua escrita. São atividades que dão ênfase à prática de "sons isolados em palavras e frases. Consistem em escutar, repetir, classificar, discriminar, ler e/ou completar textos” (RIGOL, 2005, p. 193) e costumam ser encontradas nas unidades em uma seção denominada Pronunciación y Ortografía, em um anexo ou no caderno de exercício, salvo exceções.

Segundo McNerney e Mendelsohn (1992, p.186, apud ALVES E BARRETO, 2012, p. 241): "Um curso de pronúncia de pequena duração deve focalizar primeiramente os aspectos suprassegmentais, uma vez que eles exercem o maior impacto na compreensibilidade da fala do aprendiz".

Segundo Cristófaro Silva (2014), a consciência fonológica é um termo relacionado ao conhecimento que os falantes têm da organização da sonoridade e acrescenta que os sons que reproduzimos por meio da fala é exteriorizada ao pronunciarmos as palavras. Ainda, argumenta que há indícios de que os falantes são, de fato, capazes de identificar nas palavras sons individuais.

Entretanto, além de identificar sons individuais, um falante é capaz de separar palavras em sílabas, perceber o tamanho de uma palavra em relação a outra, identificar semelhanças sonoras entre palavras ou parte das palavras e é também capaz de segmentar e manipular sílabas e sons (rimar ou substituir sons específicos). O conjunto dessas habilidades é denominado consciência fonológica. Ou seja, o falante tem consciência de que as palavras faca e vaca têm duas sílabas e de que a palavra lavada tem três sílabas. O falante tem consciência de que todas as sílabas das palavras apresentadas são formadas por (consoante + vogal) e de que na palavra vasta a primeira sílaba é formada por (consoante + vogal + consoante) (CRISTÓFARO SILVA,2014, p. 01).

A autora argumenta que a consciência fonológica corresponde à habilidade de conscientemente manipular os sons, sejam elas sílabas ou palavras, desenvolvendo a consciência fonológica, permitindo o aprimoramento da generalização e memorização das correlações entre as letras e os sons. Já as autoras Cunha e Capellini afirmam que:

a consciência fonológica é uma parte integrante da consciência metalinguística, está relacionada à habilidade de refletir e manipular os segmentos da fala, abrangendo, além da capacidade de reflexão (consultar e comparar), a capacidade de operar com rimas, aliteração, sílabas e fonemas (contar, segmentar, unir, adicionar, suprimir, substituir e transpor) (CUNHA; CAPELLINI, 2011, p. 87).

A Consciência fonológica para Scherer (2012, p.23) “é a habilidade reconhecer e manipular os sons que compõem a fala. É estar consciente de que a palavra falada é constituída de partes que 
podem ser segmentadas e manipuladas". A autora acrescenta que o falante para ter consciência fonológica necessita ignorar o significado das palavras a ater-se a sua estrutura.

Essa habilidade exige do falante um nível mais elevado de consciência linguística, pois requer desde a consciência da estrutura da palavra até a sua separação em sons individuais, uma vez que no ato da fala não há nenhuma preocupação com as unidades sonoras constituintes das palavras, é necessário manipular corretamente os sons da língua, realizando as correspondências adequadas.

Freitas et al. (2007, p.11) conceitua consciência fonológica como a "capacidade de explicitamente identificar e manipular as unidades do oral”. Para Sim-Sim a consciência fonológica é:

\begin{abstract}
o conhecimento que permite reconhecer e analisar, de forma consciente, as unidades de som de uma determinada língua, assim como as regras de distribuição e sequência do sistema de sons dessa língua. Em contraste com as atividades de falar e de ouvir falar, a consciência fonológica implica a capacidade de voluntariamente prestar atenção aos sons da fala e não ao significado do enunciado (SIM-SIM, 1998, p. 225).
\end{abstract}

Segundo Araújo (2013, p. 28) "todo o processamento fonológico resulta da capacidade de usar conhecimentos fonológicos para organizar a linguagem oral e escrita, reunindo capacidades como a discriminação, memória e produções fonológicas, bem como a consciência fonológica".

Nascimento (2009) apud Araújo (2013, p. 28) argumenta que "o pensamento com o qual o indivíduo utiliza a estrutura fonológica ou sons da língua oral, com a finalidade de aprender a descodificá-la no plano escrito", é composto por quatro importantes conceitos:

- Consciência Fonológica;

- Discriminação Fonológica: capacidade de discriminar fonemas;

- Memória Fonológica: capacidade de memorizar palavras, sílabas e fonemas;

- Produção Fonológica: articulação das palavras e uso dos fonemas na fala.

Figura 5. A Consciência Fonológica e o Processamento Fonológico

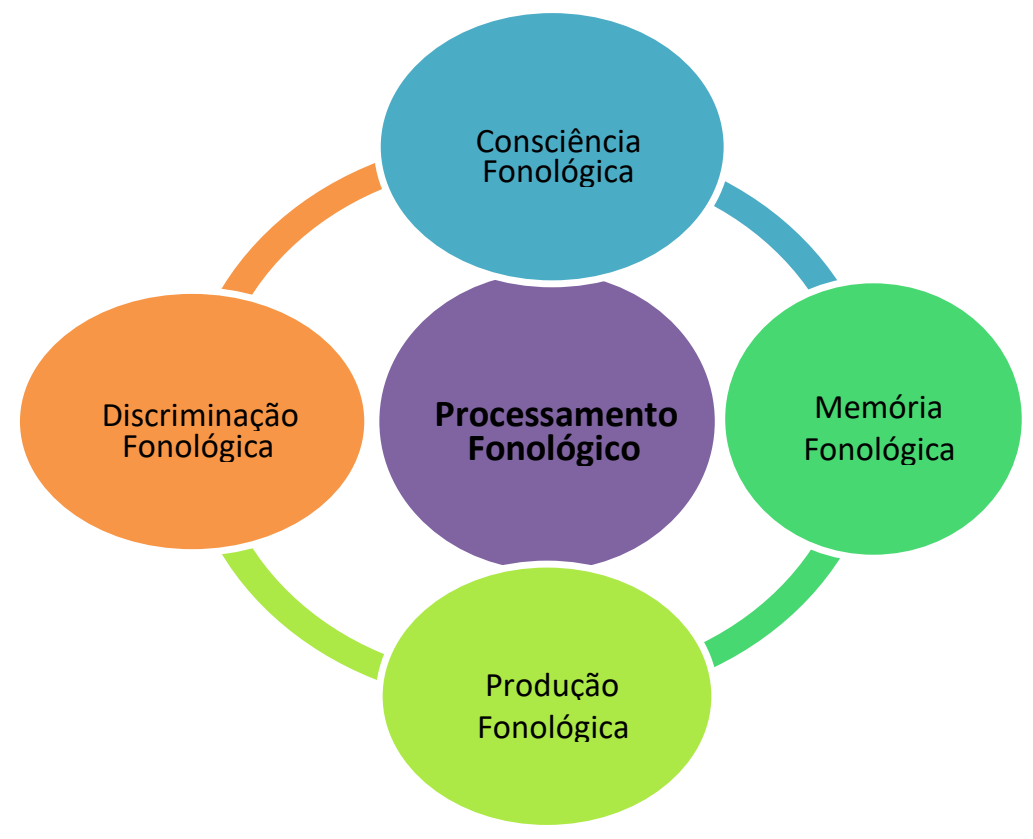

Fonte: Santos e Navas (cit. por Nascimento, 2009:5). 
Taveira e Gualberto (2012, p. 3) esclarecem que: "se os alunos não tiverem a consciência fonológica da L2, eles não saberão como monitorar seu discurso, sempre irão precisar de alguém para corrigir a sua pronúncia."

Destarte, a consciência fonológica é uma competência de suma importância para o ensino-aprendizagem de uma língua adicional, por meio dessa consciência os aprendizes discriminar as diferenças sonoras e poderão de uma forma autônoma corrigir os equívocos relacionados à fala e da pronúncia.

\section{O ENSINO DA PRONÚNCIA EM CONTEXTO DE FRONTEIRA}

O cenário destaca duas cidades gêmeas - Guajará-Mirim e Guayaramerín -, localizadas no Estado de Rondônia, no Brasil, e no Departamento de Beni, na Bolívia. As duas estão separadas pelo rio Mamoré, bastante largo, sem ponte que permita fazer a travessia, realizada por meio de lanchas motorizadas as quais cobram valores relativamente baixos na prestação deste serviço. Segundo Silva et al.,

na fronteira Brasil-Bolívia esses fatores são motivados pelas relações comerciais, trabalhistas, educacionais e culturais entre brasileiros e bolivianos. Este trabalho descreve o funcionamento dos sentidos das línguas para os sujeitos fronteiriços, em cenas cotidianas, ou seja, o contato diário com o "outro", a partir das diferentes relações estabelecidas, considerando as línguas como fortes elementos que se constituem em espaços de circulação nesta zona fronteiriça. Desta maneira, as relações de convivência entre os sujeitos fronteiriços são interpretadas por meio dos diálogos produzidos (SILVA et al., 2009, p. 04).

O maior movimento na travessia ocorre do lado brasileiro para o lado boliviano, denominado localmente de La banda; o comércio de importados é intenso e recebe visitas diárias de inúmeros brasileiros para fazer compras. A situação não é diferente no lado brasileiro, que diariamente também recebe bolivianos em busca de produtos alimentícios, entre outros, porém em quantidade menor que o fluxo em direção contrária.

As circunstâncias linguísticas nesta região são bem distintas das que predominam em outras cidades gêmeas, provavelmente pela situação do acesso entre elas, que não é tão prático como em outras fronteiras. A zona comercial boliviana começa bem no terminal portuário e se estende por aproximadamente dez quadras na avenida principal. Além da ausência de ponte para fazer o cruzamento entre as duas cidades, existe ainda o medo da travessia nas pequenas embarcações que não apresentam muita segurança - o que enfraquece o contato entre as duas cidades.

A cidade de Guayaramerín foi fundada em 1892, devido à importância do setor agrícola na região, principalmente a exportação da borracha e da castanha. Atualmente, a principal atividade econômica é o comércio com o vizinho Brasil.

A região fronteiriça de Guayaramerín e Guajará-Mirim destaca-se por sua grande diversidade linguística e cultural: além do português e do espanhol, são faladas muitas outras línguas indígenas como: Oro uin, uari e urupá. É nesse ambiente sociolinguístico que pretendemos refletir acerca das implicações das variações linguísticas no âmbito escolar.

A oportunidade de se comunicar em língua estrangeira, conhecer outras realidades e, principalmente, de se sentir capaz de realizar determinadas tarefas em uma língua que não é a sua cons- 
titui fator de motivação para aprender não só a língua, mas também outros elementos que fazem parte da cultura, como uma contribuição a mais para refletir sobre sua própria realidade. Ruiz e Döring afirmam que

hoje temos a convicção de que a linguagem é adquirida por uma necessidade de comunicação baseada em aptidões humanas para a linguagem, exposta a um meio linguístico específico, e num processo dinâmico e criativo intimamente relacionado com a evolução da pessoa (RUIZ; DÖRING, 2002, p. 384, tradução nossa ${ }^{4}$ ).

Para que os estudantes de língua situados na fronteira entre Guajará-Mirim e Guayaramerín desenvolvam competência linguística e comunicativa em português brasileiro (PB), é de extrema importância que os professores deste idioma sejam capacitados e tenham o máximo de domínio das variações linguísticas da região, dando dinamismo ao processo de ensino-aprendizagem.

É grande a busca de cursos de idiomas, tanto por brasileiros que desejam aprender o espanhol como de bolivianos, venezuelanos, argentinos e uruguaios que desejam aprender o português.

O curso de Medicina ofertado pela Universidad Autónoma del Beni impulsionou a procura pelos cursos de português no Brasil, já que, anualmente, recebe diversos alunos de todo o Brasil; por este motivo, professores e servidores buscam capacitação linguística, no intuito de compreender melhor os estudantes brasileiros. Ademais, há muitos comerciantes hispanofalantes, para quem uma comunicação bem-sucedida pode ser o diferencial para fazer negócios melhores.

Segundo a página na internet do Instituto Federal de Educação, Ciência e Tecnologia de Rondônia (IFRO), o Português como Língua Adicional (PLA) passou a ser o terceiro curso ofertado por meio do programa e-Tec Idiomas Sem Fronteiras: o Campus Guajará-Mirim, desde 2016, oferta cursos de PLA para alunos bolivianos que residem em Guajará-Mirim e Guayaramerín. O Instituto, no mesmo ano, ofertou cursos de inglês e espanhol à comunidade interna e externa em todos os campi do IFRO.

\section{Análise do material didático}

O material analizado é o caderno 1 intitulado "Aula 1: Bem-vindo ao condomínio Brasil!" Para análise da obra escolhe-se uma mostra de uma atividade, de um diálogo da midia integrada e de trechos que paresentam alguma menção ao ensino da pronúncia, fonética, fonologia ou variação linguistica.

Na seção "Para começo de conversa" é apresentado o condominio Brasil, que é usado como pretexto para o desenvolvimento de situações comunicativas, em que os aprendizes estudarão conteúdos relacionados a saudações e despedidas, o alfabeto a flexão de substantivos e o verbo ser para que possam interagir em situações que requer o uso de uma apresentação pessoal.

Na seção "Comunicando-se" é apresesentasdo o episódio Bem-vindo do Condomínio Brasil, representado pelas personangens Marta e Léo que se encontram no interior do prédio e utilizam algumas expressões de saudação, cortesia e despedida. O diálogo está na midia integrada por meio de um vídeo e no caderno do estudante.

4 No original: "hoy se tiene la convicción de que el lenguaje se adquiere por una necesidad de comunicación a partir de las aptitudes bumanas para el lenguaje, expuestas a un medio linguístico determinado, y en un proceso dinámico y creativo intimamente relacionado con la evolución de la persona". 
Figura 6. Episódio Bem-vindo ao Condomínio Brasil

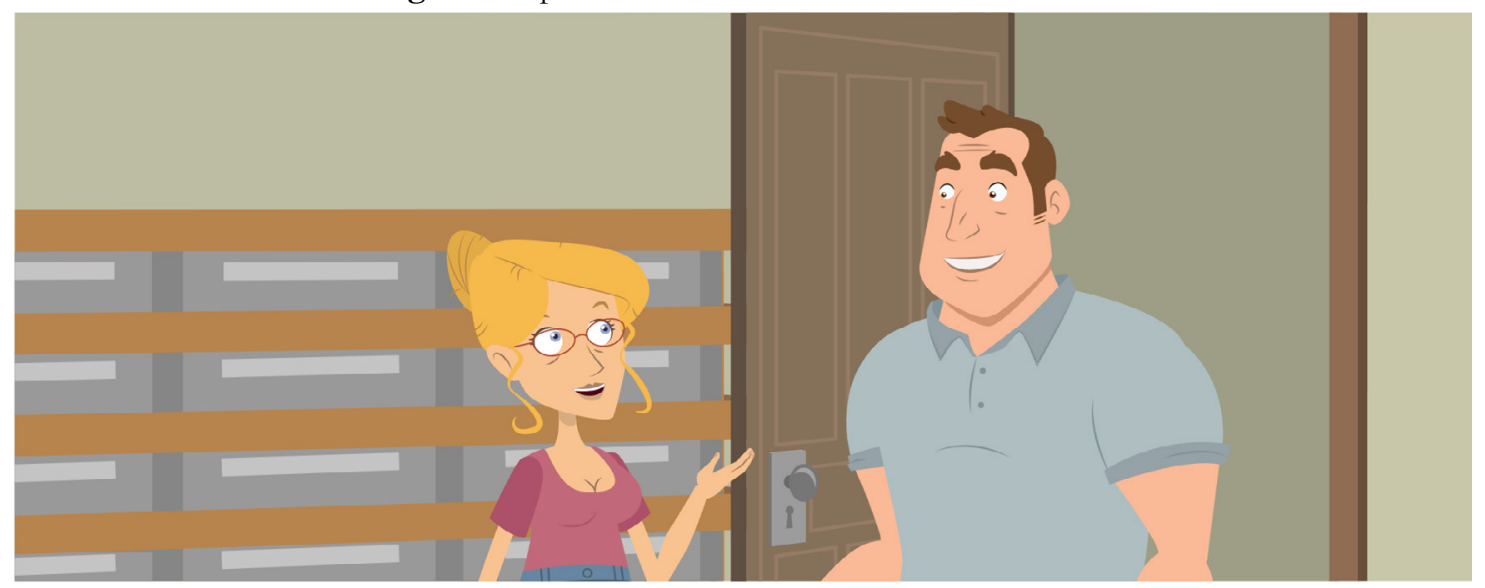

Fonte: Brasil (2015, p. 16).

Marta: Bom dia! você é porteiro?

Léo: Perdão. Como?

Marta: Sou a nova moradora do 702, Marta, Marta Reis.

Léo: Ah, sim. Meu nome é Léo, sou o síndico. Muito prazer. Seja bem-vinda! Não sabia que você chegava hoje! Desculpa a confusão. Os Silveira estão deixando o prédio. Está tudo um caos... Eu tinha entendido que você viria somente na quinta.

Marta: Na verdade, houve uma mudança de planos. Minha mudança deve vir mais tarde, mas já trouxe algumas malas comigo. Deixei tudo na portaria, como ainda não tenho as chaves...

Léo: Ah, claro! O corretor as deixou comigo. Já pego para você. Pode subir que já alcanço suas bagagens também. Seu apartamento é o 702, não é? [...] Prontinho, aqui estão suas malas, Marta. De onde você está vindo?

Marta: Sou daqui da cidade mesmo.

Léo: Com o que você trabalha?

Marta: Sou escri....hã...escultora.

Léo: Nossa! Que legal! Sabe, uma vez eu estive em um museu, na Holanda...

Marta: Desculpa, mas eu estou um pouco cansada... Tem mais alguma mala?

Léo: Acho que essa era a última. Se precisar de mais alguma ajuda, é só chamar, viu? Apartamento 202.

\section{Marta: Está bem, muito obrigada, Zé. Até logo!}

Léo: É Léo. Meu nome é Léo.

Ao assistir o vídeo do didálogo, percebe-se que as personagens Leó e Marta utilizam a variante do Sul do Brasil É importante pontuar que o áudio apresenta uma comunicação mecanizada, proporcionando ao aprendente um distanciamento da realidade linguística.

A seção "De Olho no Português Brasileiro" retoma o conteúdo saudações e despedidas, o material explana as formas de tratamento são utilizadas no cotidiano do brasileiros, formais e informais, e em quais a linguagem por meio de gestos (beijos, abraços e apertos de mãos) podem ser utilizadas. Cabe ressaltar que a obra utiliza contrastes, notas explicativas e glossários em espanhol que pode facilitar o entendimento do aprendente hispanofalante. 
No análise do LD, descobriu-se que a página 21 traz uma explicação sobre o uso do verbo ser, que no PB pode vir ou não acompanhado do pronome expresso na frase.

$\mathrm{Na}$ página 22, o livro traz $\mathrm{O}$ alfabeto da língua portuguesa e ressalta a importância do alfabeto na compreensão e resolução de problemas na comunicação por meio da soletração das letras do alfabeto para que o locutor e interlocutor possam se compreender.

Figura 7. Fragmento do Alfabeto da Língua Portuguesa

\begin{tabular}{|c|c|c|}
\hline \multicolumn{3}{|c|}{ ALFABETO DA LÍNGUA PORTUGUESA } \\
\hline Letra & Nome da letra & Exemplos de pronúncias \\
\hline \multirow{2}{*}{$\mathrm{A} / \mathrm{a}$} & \multirow{2}{*}{$\mathrm{a}$} & amigo \\
\hline & & amanhã \\
\hline \multirow{2}{*}{$\mathrm{B} / \mathrm{b}$} & \multirow{2}{*}{ bê } & bala \\
\hline & & Brasil \\
\hline \multirow{5}{*}{$\mathrm{C} / \mathrm{c}$} & \multirow{5}{*}{ cê } & casa \\
\hline & & cebola \\
\hline & & cinema \\
\hline & & coração \\
\hline & & curioso \\
\hline \multirow{2}{*}{$\mathrm{D} / \mathrm{d}$} & \multirow{2}{*}{ dê } & dia \\
\hline & & doce \\
\hline \multirow{2}{*}{$\mathrm{E} / \mathrm{e}$} & \multirow{2}{*}{ ê/é } & estudante \\
\hline & & ego \\
\hline \multirow{2}{*}{$\mathrm{F} / \mathrm{f}$} & \multirow{2}{*}{ efe } & felicidade \\
\hline & & fome \\
\hline \multirow{6}{*}{$\mathrm{G} / \mathrm{g}$} & \multirow{6}{*}{ gê } & gato \\
\hline & & gente \\
\hline & & guerra \\
\hline & & girassol \\
\hline & & guichê \\
\hline & & goleiro \\
\hline
\end{tabular}

Fonte: Brasil (2015, p. 21).

O LD traz o alfabeto baseado Masip (2015), o qual apresenta a letra, o nome da letra e exemplos de palavras e possiveis pronúncias. $\mathrm{Na}$ análise material, não há ocorrência de referências 
quanto ao modo ou ponto de articulação dos sons do PB. Em seguida o livro sugere uma atividade de fixação como podo-se observar na imagem abaixo,

Figura 8. Atividade de aprendizagem

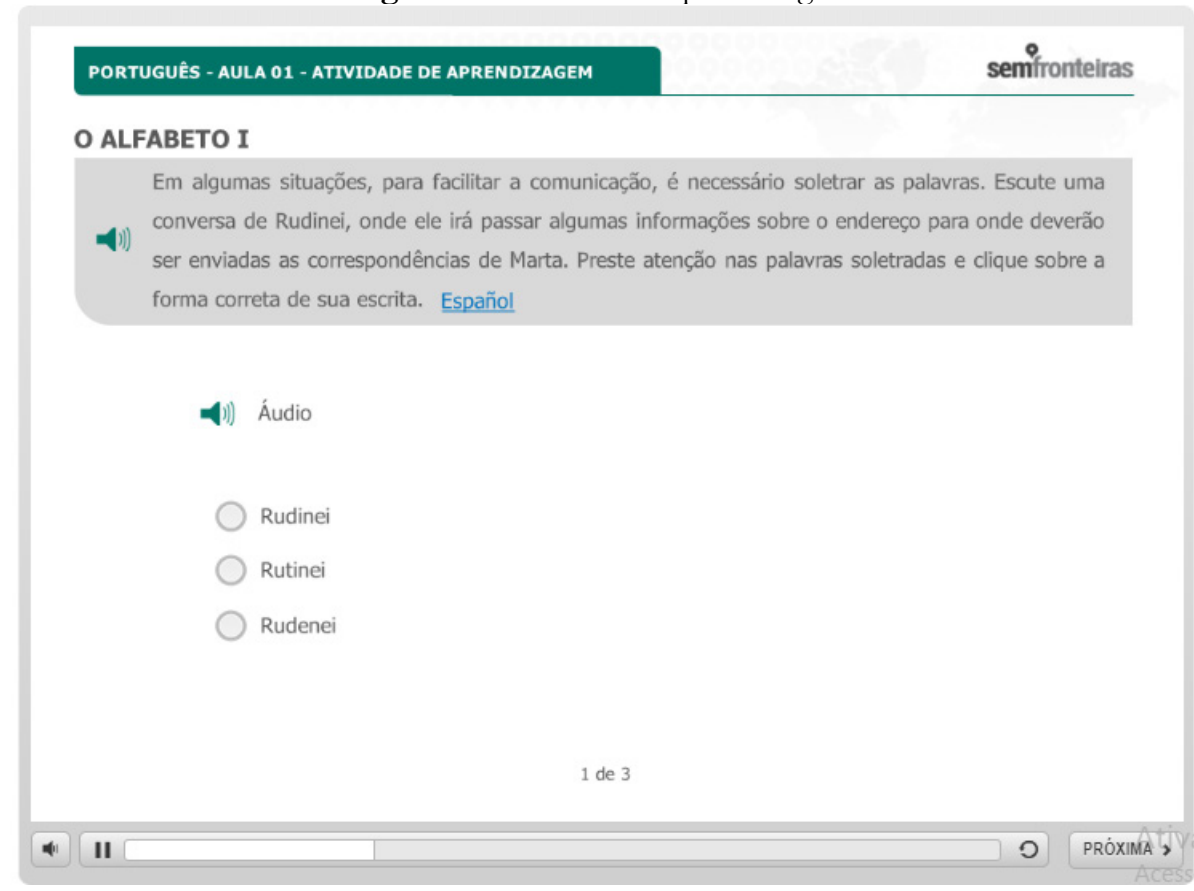

Fonte: Brasil (2015)

Observa-se que a atividade não desenvolve competências de consciência fonológica, o exercício baseado apenas na soletração e não há realização de Feedback das questões. O ensino da pronúncia aparece implicitamente na atividade e não explora as variedades linguísticas do PB.

Na seção "Síntese", é relizada uma síntese dos contúdos estudados, no que diz respeito ao ao alfabeto, o livro afirma o alfabeto permite o aperfeiçoamento da pronúncia, mas não dá subisidios para que isso aconteça, já o enfoque é baseado nos conteúdos gramaticais.

\section{CONSIDERAÇõES FINAIS}

Concluímos que o livro analisado não possui seções específicas para o ensino de pronúncia e não explora as diferentes variedades linguísticas do português. Observou-se que os áudios da mídia integrada priorizam apenas as variedades do português do sul do Brasil, o que pode estimular nos alunos uma falsa sensação de homogeneidade linguística, além de dificultar o ensino de pronúncia para os aprendizes residentes em cidades fronteira, tendo em vista que eles estão em contato com outras variedades do português. Além disso, os materiais didáticos limitam-se à abordagem comunicativa, e muitos docentes fazem adaptações para poder adequar o material às necessidades do público-alvo. As atividades não facilitam a aprendizagem da pronúncia do Português Brasileiro (PB), conceitos básicos de fonética e fonologia e as atividades presentes em todos as aulas do módulo 1 são de caráter tradicional e não desenvolvem as competências de consciência fonológica.

Acreditamos que este estudo contribuirá para a reflexão sobre o papel dos materiais didáticos no ensino da pronúncia de PLA, pois oportuniza a discussão sobre a adequação desses livros frente às necessidades de alunos e professores que participam do processo de ensino-aprendizagem de PLA. 


\section{REFERÊNCIAS}

ALLEGRO, F. R. P. Ensino de pronúncia em Português língua estrangeira: análise de livros didáticos. Tese (Doutorado em Linguística) - Pontifícia Universidade Católica de São Paulo, São Paulo, 2014.

ALMEIDA FILHO, J. C. P. (Org.). Aspectos suprassegmentais da fonologia do Português na perspectiva do professor de PLE. In URAZZA, J. S. (Org.) ; BUTI, C. (Org.) Estudos em Português Língua Estrangeira. 1. ed., São Paulo: Paco Editorial, v. 1, 2016.

ALMEIDA FILHO, J. C. P. O ensino de português como língua não-materna: concepções e contextos de ensino. 2008. Disponível em: http://bit.ly/2RmAS7w. Acesso em 20/06/2019 às 22:30 http://bit. ly/35STsJi.

ALMEIDA FILHO, J. C. P. Ensino de português língua estrangeira/EPLE: a emergência de uma especialidade no Brasil. In LOBO, T.; CARNEIRO, Z.; SOLEDADE, J.; ALMEIDA, A.; RIBEIRO, S. (Orgs.). Rosae: linguística histórica, história das línguas e outras histórias [online]. Salvador: EDUFBA, 2012, pp. 723-728 ARAÚJO, M. N. S. P. O Valor da Consciência Fonológica em Alunos com Português Língua Não Materna. Dissertação (mestrado em Educação e Organização de Bibliotecas Escolares) Instituto Politécnico da Guarda Escola Superior de Educação, Comunicação e Desporto, 2013.

BAKHTIN, M. Estética da criação verbal. São Paulo: Martins Fontes, 2003.

BARBOSA, M. H. Questões de pronúncia e inteligibilidade em contexto de inglês como língua estrangeira. Dissertação (Mestrado) - Pontifícia Universidade Católica de São Paulo, São Paulo, 2013.

BARRETO, F. M.; ALVES, U. K. "Como inserir o ensino comunicativo de pronúncia na sala de aula de L2”, In: Consciência dos sons da língua: subsídios teóricos e práticos para alfabetizadores, fonoaudiólogos e professores de língua inglesa. 2. ed. rev., Porto Alegre: EDIPUCRS, 2012, pp. 231-258.

BAUER, D. A.; ALVES, U. K. O ensino comunicativo de pronúncia nas aulas de inglês (L2) para aprendizes brasileiros: análise de um livro didático. Linguagem \& Ensino, Pelotas, v.14, n. 2, jul/dez. 2011, p. 287-314. BLANCO, A. Análisis del cubrimiento dado a la pronunciación en manuales vigentes de E/LE: recomendaciones para optimizar su inclusión en el Enfoque Comunicativo. Dissertação (Máster europeo en aprendizaje y enseñanza de español en contextos multilingües e internacionales), Universidad Libre de Berlín, 2014.

BRASIL. Português: módulo 1-caderno 1. Andrea Ualt Fonseca [et al.]; Coordenadora: Denise Pérez Lacerda. Pelotas: IFSul, 2015.

CARVALHO, M. V. Uma política científica com visão estratégica não pode deixar de considerar prioritária a valorização do português como língua científica internacional. CRISTÓFARO-SILVA, T. Consciência fonológica. In: Glossário Ceale: termos de alfabetização, leitura e escrita para educadores. FaE UFMG, 2014. CUNHA V. L. O; CAPELLINI, S. A. Habilidades metalinguísticas no processo de alfabetização de escolares comtranstornos de aprendizagem. Revista de Psicopedagogia, 2011, p. 85-96.

ESCARPINETE, M. L. A formação docente e o ensino de PLE. In: Jornada Nacional do grupo de Estudos Linguísticos do Nordeste, 2012.

FALCÃO, C. A. O ensino da pronúncia do espanhol na educação à distância: uma proposta didática. In: Anais da XXIV Jornada Nacional do Grupo de Estudos Linguísticos do Nordeste, 2012.

FARIAS, M. S. O ensino da pronúncia nos manuais de espanhol como língua estrangeira. Anais do I Simpósio Interdisciplinar de Estudos Linguísticos, UECE, 2015.

FERNÁNDEZ, J. G. Fonética para profesores de español: de la teoría a la práctica. Madrid: Arco/Libros, 2007

FREITAS, M. J.; ALVES, D.; COSTA, T. PNEP - O conhecimento da Língua: Desenvolver a consciência fonológica. Lisboa: Ministério da Educação, 2007.

GIL FERNÁNDEZ, J. Fonética para professores de español: de la teoría a la práctica. Madri: Arco Libros, 2007.

IFRO. Professores realizam capacitação em Português como Língua Adicional. Disponível em http://bit. ly/30qxYm7. Acesso em: 10 fev 2019. 16:50:10. 
IRUELA GUERRERO, A. ¿Qué es la pronunciación? redELE: Revista Electrónica de Didáctica en ELE, n. 9, 2007. Disponível em: http://bit.ly/36UVhXD. Acesso em 09 set. 2019.

LLISTERRI, J. La enseñanza de La pronunciación. In: Revista del Instituto Cervantes en Italia, v. 4, 2003, p. 91-114.

MACHADO, T. R. M. O Exame Celpe-Bras e o funcionamento do sentido da brasilidade. Dissertação (Mestrado em Letras) - Universidade Federal de Santa Maria, Porto Alegre, 2011.

MELO, D. T. M. [et al.]. Considerações sobre a docência de Português como Língua Estrangeira. Calidoscópio, v.11, n.1, 2013, p. 14-20.

NASCIMENTO, L. C.; KNOBEL, K. A. Habilidades Auditivas e Consciência Fonológica: da teoria à prática. São Paulo: Pró-Fono, 2009.

PERNA, C. L.; SUN, Y. Aquisição de português como língua adicional (PLA): o uso de hedges em português por falantes nativos de mandarim. Letras de Hoje. Porto Alegre, v. 46, n. 3, jul./set. de 2011, p. 59-70.

RIGOL, M. B. La pronunciación en la clase de lenguas extranjeras. Revista PHONICA 1, 2005.

RUIZ, P. G.; DÖRING, G. B. El modelo dialógico en la enseñanza-aprendizaje de una le (hacia una pedagogía de la interculturalidad). Actas de la Asele. XIII Congreso Internacional de la ASELE.El Español, Lengua del Mestizaje y la Interculturalidad. Murcia, 2002.

SCHERER, A. P. R.; BARRETO, F. M.; BRISOLARA, F. B.; SANTOS, R. M.; ALVES, U. K. Consciência dos sons da língua: subsídios teóricos e práticos para alfabetizadores, fonoaudiólogos e professores de língua inglesa. 2. ed., rev., Porto Alegre: EDIPUCRS, 2012, pp. 231-258.

SILVA, R. V.; RAVANELLI. M. S.; RIVAS, V. E.; GAERTNER, L. G. Línguas em contato e aspectos da integração linguística em uma das fronteiras Brasil/Bolívia. In: Despertar para a fronteira. Campo Grande, MS: Ed. UFMS. 2009.

SIM-SIM, I. Desenvolvimento da Linguagem. Lisboa: Universidade Aberta.1998.

TAVEIRA, V. R. Fonologia: ferramenta de ensino para professores de inglês como língua estrangeira. Pesquisas em Discurso Pedagógico, 10.17771. PUC-Rio. PDPe.20887. 2012.2

ZOPPI-FONTANA, M. G.; DINIZ, L. R. A. Declinando a língua pelas injunções do mercado: institucionalização do Português Língua Estrangeira (PLE). Estudos Linguísticos, v. 37, 2008, p. 89-119. 